\title{
Impact of Floods on Vegetation Cover in the Sanghar District of Sindh, Pakistan
}

\author{
Zenobia Talpur *, Talal Naseer , Abdul Rafay Memon and Arjumand Zaidi
}

US Pakistan Center for Advanced Studies in Water, Mehran University of Engineering \& Technology, Jamshoro, Sindh, Pakistan; talalnaseer15@gmail.com (T.N.); memonabdulrafay86@gmail.com (A.R.M.); arjumand.uspcasw@faculty.muet.edu.pk (A.Z.)

* Correspondence: zenobia.talpur@gmail.com.

\begin{abstract}
This study aims to assess the impact of 2010-2011 flash floods on the crop production of Sanghar-an eastern district of Sindh. The population of almost two million is mainly dependent on agriculture. Cotton, sugarcane, and wheat are the main cash crops of the district. In 2010-2011 Sanghar was hit by flash floods after heavy rainfall. These floods adversely affected the crops standing at that time. However, on the other hand, they increased the fertility of agriculture lands. Satellite images, precipitation data, and geographical information system (GIS) tools were used to quantify floods' effects by mapping pre- and post-flood vegetation cover. Supervised classification was applied on Landsat images from 2009 to 2013 to extract vegetation area. The temporal analysis unveils a significant increase in the vegetation cover in the post-flood years. Furthermore, the comparison between pre-and post-flood crop production data collected from the Pakistan Bureau of Statistics also validated the study results by revealing an increase in crop production.
\end{abstract}

Keywords: flash floods; GIS; impact of floods; landsat; satellite images; vegetation cover

\section{Introduction}

In Pakistan, an unprecedented 100-years flood began in July 2010 from heavy monsoon rains in Sindh and other Pakistani regions. About 20 million people were affected. The flood inundated almost one-fifth of Pakistan's total land area, mostly by destroying agriculture lands, property, and infrastructure [1]. Displacement of thousands of people and livestock and the collapse of water, sanitation, and health system were some of the 2010 flood aftermaths. This situation also caused widespread unrest among a more vulnerable population comprising children, women, and the elderly [4]. In short, this flood badly affected most parts of the Indus River basin.

\subsection{Flash Floods in Sindh}

There are two types of floods occurring in the Sindh province-riverine floods and flash floods. The former is unsurprising and provides enough time to react, whereas, in the case of a flash flood caused by heavy rainfalls, there is usually no time to respond. Flash floods have low frequency and duration but higher intensity due to which their impacts are immense and devastating. These floods mostly occur in the monsoon months of July and August [2].

The 2010-2011 floods impacted mostly the agriculture sector of Pakistan, leading to significant economic losses. Agriculture contributes $21 \%$ of Pakistan's GDP, $45 \%$ in employment, and $60 \%$ in exports [3]. In 2010, heavy rainfalls caused flash floods in the northern and south-western provinces of Pakistan, whereas it took some time to enter Sindh situated in the country's south-east region. The disaster resulted in a loss of 7.5 million tons of sugarcane and 0.7 million tons of cotton and affecting $20 \%$ of Pakistan's total landmass causing total damage of more than $\$ 10$ billion [3]. The 2011 flash floods mostly affected the Sindh province.

\subsection{Impact of Floods in the Sanghar District}

Sanghar is one of Sindh's largest districts, with an area of 9874 Sq.km and a population of almost 20 million, which rely on agriculture. Figure 1 illustrates the study area. This region is not a riverine 
flood-prone area, but it experiences heavy rainfall in the summer and monsoon season from July to August. Due to which the frequent flash floods occur [4].

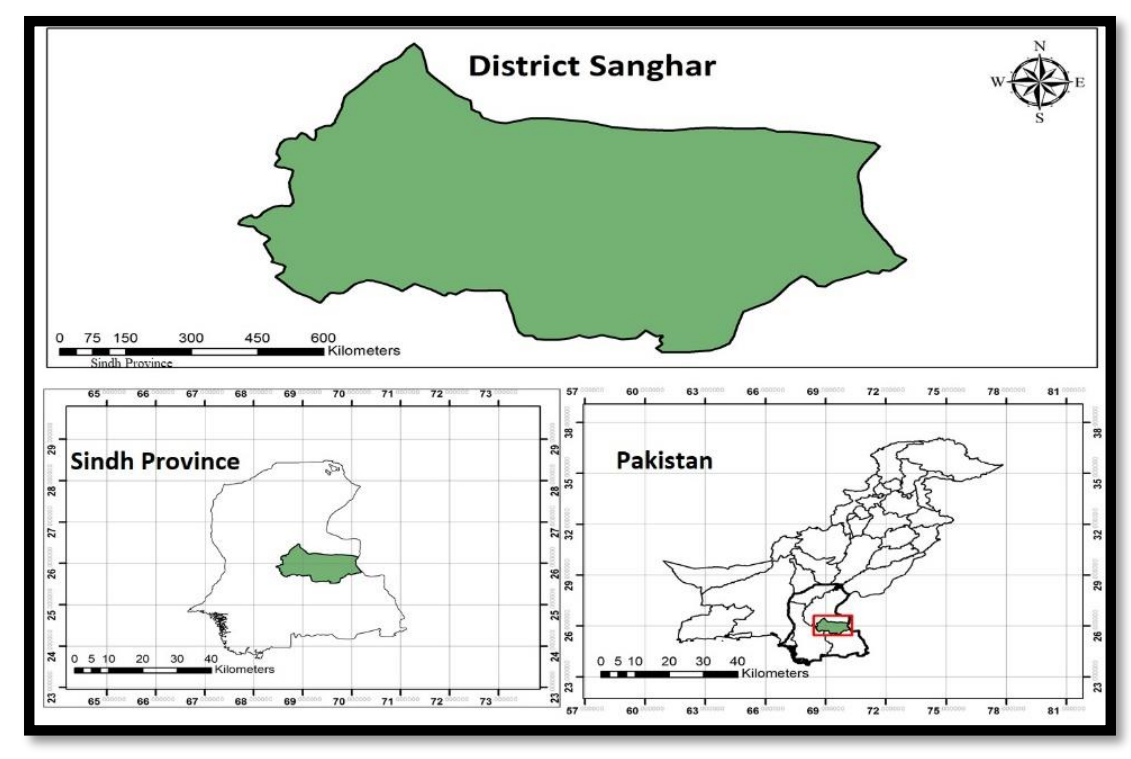

Figure 1. District Sanghar.

Floods have an impact on both communities and individuals and have environmental and economic outcomes as well. Their effects may be harmful or favorable, depending on the flood's area and extent [5]. The floods of 2010-2011 occurred during the harvesting period in the district, imposing considerable losses to the crops and farmers' community. The standing crops of the district were adversely affected by these flash floods. Besides the negative impacts of these floods in agricultural damages, some positive effects were also observed. A barren area comprising $50 \%$ of the landmass received a massive amount of water full of nutrients. Floods distributed and deposited river sediments over large land areas, which helped replenish nutrients in the topsoil and made agricultural lands more fertile.

\section{METHODOLOGY}

\subsection{Study Data}

In this study, satellite images of district Sanghar were used for land-use/cover (LULC) classification. The Landsat images were downloaded free of cost from the Earth Explorer USGS website. Also, crop production data from the Pakistan Bureau of Statistics (PBS) and the Sindh Agriculture Department were acquired to verify study results by comparing pre- and post-flood crop productions. Precipitation data were collected from the National Center for Environmental Prediction (NCEP) for years 2009-2013.

\subsection{Data Analysis}

Figure 2 presents the land-use/cover supervised classification of the Sanghar district using ArcMap's maximum likelihood classification tool. Further, the Normalized Difference Vegetation Index (NDVI) was utilized to identify variation in the vegetation cover before, during, and after flood years.

A total of 30 images of different harvesting seasons were downloaded from pre- and post-flood years, as shown in Table 1. The pre-flood months were considered as the base period for this study. Land-use/cover classification and deviation of NDVI from the base year were calculated to identify changes during the study period. Change in vegetation from mean has been taken as an indicator of flood impact. The negative NDVI values indicated a decrease in vegetation cover, whereas the 
positive values denoted an increase in vegetation from the base year. Further, the change in vegetation from flood years was also calculated for post-flood years to evaluate the flood's impact.

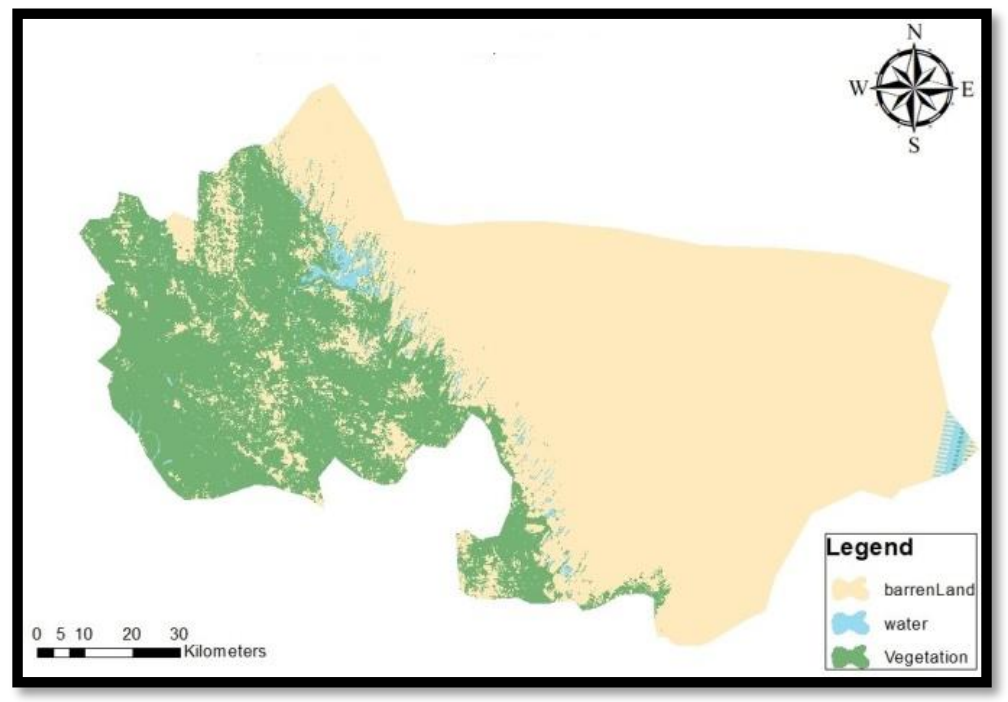

Figure 2. Land use Classification of District Sanghar.

Table 1. Distribution of Flood Years.

\begin{tabular}{cc}
\hline Description of years & Periods \\
\hline Base Year / Pre-Flood & $2009 / 06 / 05-2009 / 09 / 30$ \\
\hline Flood Years & $2010 / 06 / 05-2011 / 09 / 30$ \\
\hline Post Flood years & $2012 / 06 / 05-2013 / 09 / 30$ \\
\hline
\end{tabular}

\section{Results}

Figure 2 shows the land use classification in which barren land is shown in sandy color; green shows vegetation, and the light blue color presents water. Figure 3 presents the annual precipitations from 2009 to 2013. More than $500 \mathrm{~mm}$ precipitation was recorded in 2011, which became the main reason to cause the 2011 flash flood. Also, in 2010 and 2013, rains were more than the normal value. Figure 4 displays the variation in NDVI. Negative NDVI values represent barren land, and the positive values indicated the presence of vegetation.

In comparison to the 2009 LULC, the green area has increased after the flood of 2010-2011. Figure 5 illustrates the LULC classified areas in Sq.km. Vegetation cover increased in flood years of 20102011 and decreased in 2013. This increase identifies a positive impact on vegetation after the floods. However, this impact did not sustain in the following years. Figure 6 shows an increase in wheat production, sugarcane, and cotton crops during the flood years. The graph presents a notable rise in cotton and sugarcane production in post-flood years (crop production unit is Bales). 


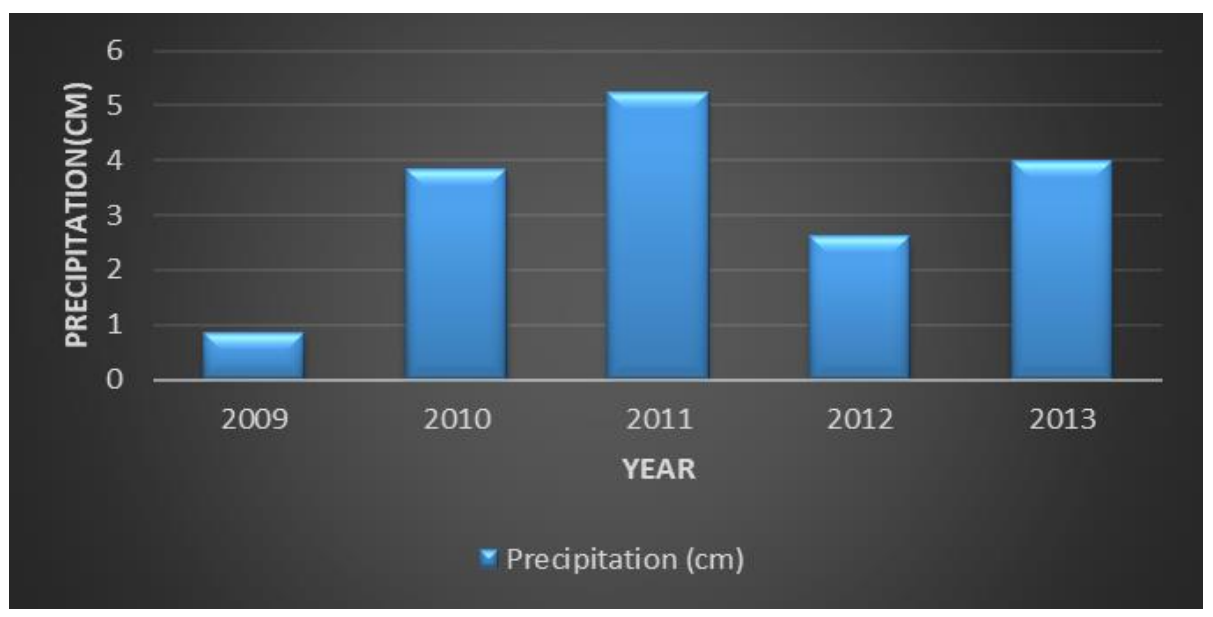

Figure 3. Precipitation.

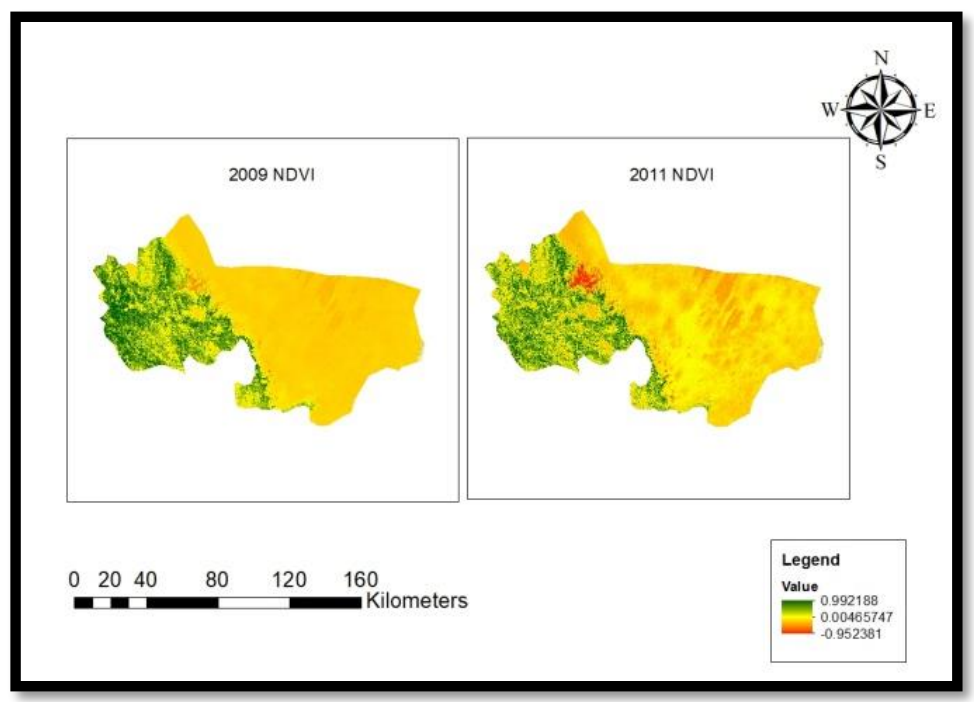

Figure 4. Variation in NDVI.

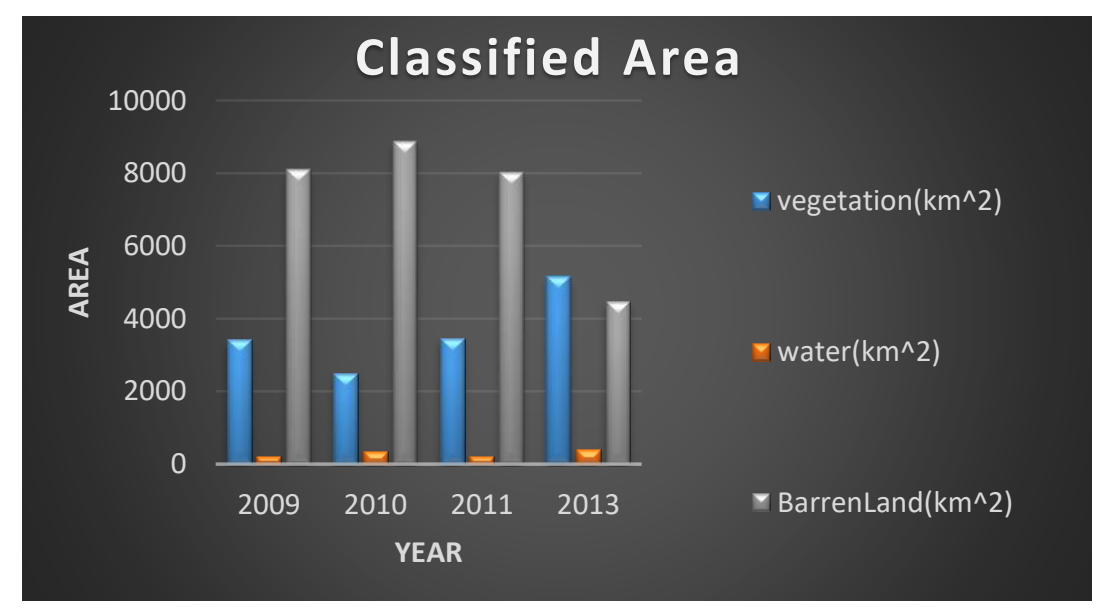

Figure 5. Classified Area. 


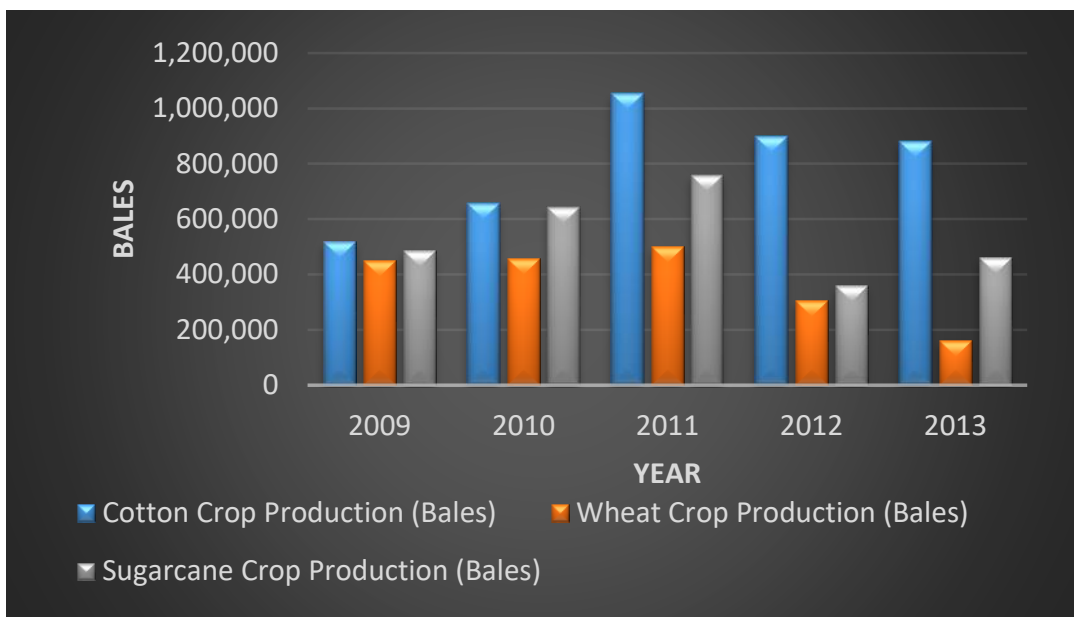

Figure 6. Crop Production.

\section{Discussions}

This study is mainly based on the impacts of flash floods on vegetation cover/crops in the district Sanghar Sindh, Pakistan. Heavy and vigorous rainfall spells were the leading cause of floods in 20102011, which affected Sindh's agricultural land, Pakistan. To assess these floods' impact on the vegetation cover in district Sanghar, Landsat images of per and post-flood period were analyzed. Initially, the crops were adversely affected due to the floods but soon after the floods, and there was an increase in the vegetation cover and crop production. This was mainly due to the new layer of fertile soil and minerals that has been deposited into the fields by the floods. This shows the positive impact of a flash flood on agriculture. Hence proper flood management in the area may mitigate the adverse effects of floods while enhancing its positive influence on the agricultural land of the Sanghar district by improving soil fertility.

\section{Conclusions}

1. Although crops were severely affected during the flood, soon after the flood, an increase in the vegetative cover presented a positive impact of the disaster.

2. This study also validated the reports of different news and media agencies about the positive impacts of the flood in the Sanghar district.

3. Data and results from the Pakistan Bureau of Statistics (PBS) and Agriculture Department Sindh also validated the study result by showing an increase in crop production and vegetation cover in the Sanghar district.

4. Although the positive impact of floods, possibly due to the addition of fertile soils, is evident from study results, this impact could not sustain long. Therefore, it is suspected that the positive effect of the flood was temporary. Analyzing more extended post-flood satellite data will reveal the actual situation.

\section{Recommendations}

1. Further extended period studies should be carried out with field surveys to analyze the positive and negative impacts of the floods on the Sanghar district and its effects on crop production.

2. Disaster Risk Management Plan of district Sanghar, which is already drafted [9], should be implemented and incorporated in decision making.

Acknowledgments: We are thankful to Mashooq Leghari, Deputy Director of the Agricultural Department of Sanghar, for providing us the required data used in this study.

Author Contributions: Zenobia Talpur and Abdul Rafay analyzed the data; Zenobia Talpur, Talal Naseer, and Arjumand Zaidi contributed materials/analysis tools; Zenobia Talpur and Talal Naseer wrote the paper; Arjumand Zaidi reviewed the manuscript. 
Conflicts of Interest: The authors declare no conflict of interest.

\section{Abbreviations}

The following abbreviations are used in this manuscript:

GDP: Gross domestic product

GIS: Geographical Information System

LULC: land-use/cover

NCEP: National Centers for Environmental Prediction

NDVI: Normalized Difference Vegetation Index

PBS: Pakistan Bureau of Statistics

USGS: United States Geological Survey

\section{References}

1. Pakistan battles economic pain of floods by Sajjad Tarakzai August 19, 2010, Available: https://web.archive.org/web/20100927062703/http://www.thejakartaglobe.com/afp/pakistan-battleseconomic-pain-of-floods/392220

2. N. Memon, "Natural Disasters," 2005.

3. A. Rehman, L. Jingdong, Y. Du, R. Khatoon, S. A. Wagan, and S. K. J. E. D. E. Nisar, "Flood disaster in Pakistan and its impact on agriculture growth (a review)," vol. 6, no. 23, pp. 39-42, 2016.

4. Disaster Risk Management Plan District Sanghar, Government of Sindh http://www.pdma.gos.pk/new/Preparedness/DRM_Plan/Sanghar.pdf

5. Positive effects of floods by Mohiuddin ZakariaAugust 06, 2011 Available: https://www.thedailystar.net/news-detail-197343

6. Government of Sindh Rehabilitation Department, "Sindh provincial monsoon/floods contingency plan 2011 (DRAFT VERSION 1.0)." undated. Available: http://pdma.gos.pk/new/docs/download/13sindhcontigencyplan.pdf

7. Dawn, "Impact of floods on Sindh, December 26, 2011," From InpaperMagazine, Available: www.dawn.com/news/683298.

8. GOP, "Annual flood report 2011," Government of Pakistan, Ministry of Water and Power. Undated. Available: http://mowr.gov.pk/wp-content/uploads/2018/06/Annual-Flood-Report-2011.pdf
9. Sanghar,
D.
"District
SANGHAR".
Available: http://www.pdma.gov.pk/new/Preparedness/DRM_Plan/Sanghar.pdf

(C) 2020 by the authors. Submitted for possible open access publication under the terms and conditions of the Creative Commons Attribution (CC BY) license (http://creativecommons.org/licenses/by/4.0/). 